\title{
Tomographic Assessment of Some Neural Elements Affection in Type I Diabetic Patients
}

\author{
MOHAMED E. EL-ARABI, M.Sc.*; WAEL A. GOMAA, M.D.** and OSSAMA A. RASLAN, M.D.** \\ The Department of Ophthalmology, Faculty of Medicine, Zagazig* and Ain Shams** Universities
}

\begin{abstract}
Background: Diabetic Retinopathy (DR) is the most common cause of blindness, affecting $1.9 \%$ of patients with DM. Furthermore, $2.64 \%$ of diabetic patients have visual Sight-Threatening Diabetic Retinopathy (STDR). The major cause of visual impairment in DM patients is Diabetic Macular Edema (DME) [1]. Although the long-term effects of D.M on vascular tissues are very well known, its effect on retinal neurons isn't very clear [2]
\end{abstract}

Aim of Study: To detect early neurodegenerative retinal changes preceding the microvasculopathy in patients with type 1 Diabetes Millets (DM) with no Diabetic Retinopathy (DR).

Patients and Methods: We measured mean Nerve Fiber Layer (NFL) and Ganglion Cell Layer (GCL) thickness by Optical Coherence Tomography (OCT) 8 ETDRS map zones, the inner circle (pericentral) and the outer circle (peripheral) area of the macula in sixty-three patients with type $1 \mathrm{DM}$ with no DR underwent full ophthalmic examination and OCT compared to 36 healthy controls.

Results: We found insignificant mean thickness difference of NFL and GCL of each ETDRS zone of patients and controls, main effect of group, $\mathrm{F}=2.952, p=.090$ by slip-plot (mixed design) ANOVA. There was insignificant interaction between group and zones of ETDRS, $\mathrm{F}=.821, p=.548$. By independent samples Student's $t$-test there were no significant difference between diabetic patients and healthy controls except in temporal zone of inner circle in the left eye was statistically significant thinning in diabetic patient by only $2.02 \mu \mathrm{m}$ which is clinically insignificant.

Conclusion: Nerve Fiber Layer (NFL) and Ganglion Cell Layer (GCL) were not affected in early type 1 diabetic patient without minimal DR in the absence of macular edema. The theory of early neurodegenerative changes preceding the microvasculopathy in DM type 1 patient is not supported. Therefore, there is no advantage in performing OCT routinely in patients with type 1 diabetes without minimal DR.

Key Words: Diabetes - Retinopathy - Optical coherence tomography.

Correspondence to: Dr. Mohamed E. El-Arabi, The Department of Ophthalmology, Faculty of Medicine, Zagazig University

\section{Introduction}

DIABETES mellitus is a worldwide pandemic disease. As of 2010, more than 200 million people had been diagnosed with diabetes, and this number is predicted to increase by $62 \%$ by 2025 . This increase is due to an increase in obesity together with the increased life expectancy of the world population. DM complications include macroangiopathy (myocardial infarction or vasculocerebral stroke) and microangiopathy (diabetic nephropathy, neuropathy, and retinopathy).

Diabetic Retinopathy (DR) is the most common cause of blindness, affecting $1.9 \%$ of patients with DM. Furthermore, $2.64 \%$ of diabetic patients have visual Sight-Threatening Diabetic Retinopathy (STDR). The major cause of visual impairment in DM patients is Diabetic Macular Edema (DME), with an annual incidence of $2.19 \%$. DME is a consequence of DR in the macular area and is secondary to retinal barrier rupture, which is in turn secondary to a range of metabolic changes brought about by hyperglycemia [1]

Although the long-term effects of D.M on vascular tissues are very well known, its effect on retinal neurons isn't very clear [2] .

Studies have indicated that neurodegenerative changes have also been found in the retina of diabetic patients, including apoptosis of retinal neuronal cells and activation of glial cells $[3,4]$.

The debate is still open as to whether diabetic retinal neuropathy is the effect of vascular diabetic retinopathy or is primarily caused by direct neurologic damage from chronic hyperglycemia. Relationships between specific inner retinal layer thicknesses and DR status, on the one hand, as a proxy for vascular damage, and specific inner retinal 
layer thicknesses and duration of diabetes, on the other hand, as a proxy for chronic hyperglycemia, may shed additional light on this debate [5]

The diagnostic strategies for early detection of DR are of high priority to avoid or prevent loss of vision in patients with diabetes. Ophthalmoscopy, fundus photography, and, if necessary, fluorescein angiography are the common techniques used to diagnose DR [6]. Recently, a sensitive, non-invasive Optical Coherence Tomography (OCT), it is now possible to measure RNFL thickness with a lowcoherence light source projected onto the retina to determine retinal thickness which not only measures Ganglion Cell Layer (GCL) axons but also muller cell processes and astrocytes to measure the effect of DM on RNFL and GCL thickness [6].

So, we aimed in our study to detect early neurodegenerative retinal changes in patients with type $1 \mathrm{DM}$ before the presence of microvascular clinical retinopathy.

\section{Patients and Methods}

Thirty six patients (29 males and 7 females) were recruited from Ain Shams University Hospitals outpatient clinic. 36 normal control subjects (31 males and 5 females) were age-matched with patients; did not have a diagnosis of any ocular disease, diabetes, or other systemic disease; and were randomly recruited from persons accompanying patients visiting the outpatient clinic of the Department of Ophthalmology between August 2016 and September 2017. All subjects were asked to participate in this observational, cross-sectional non-randomized study and gave written informed consent. This study was approved by the Institutional Review Board of Faculty of Medicine of Ain Shams University.

Patients were included if they aged from 10 to 30 years and had a diagnosis of type $1 \mathrm{DM}$ with insulin treatment for at least 5 years and either no DR or minimal DR, as determined by a retinal specialist through indirect fundoscopy and slit lamp stereo biomicroscopy. Minimal DR was defined as the presence of at least two microaneurysm and/or hemorrhage in the central retina in the absence of peripheral lesions. No DR was defined as no microaneurysms in the central retina and no lesions in the periphery. Exclusion criteria were age $<10$ or $>30$ years, Diabetic Retinopathy DR more than minimal DR, refractive errors more than $5 \mathrm{D}$ or $+5 \mathrm{D}$, media opacity, previous ocular surgery, previous diagnosis of glaucoma, uveitis, or retinal disease and systemic disease (hypertension, neu- rodegenerative, renal or hepatic). Visual acuity was measured. Best corrected visual acuity was recorded. Anterior segment examination by a slitlamp biomicroscopy to exclude any media opacity. After pupil dilation with $0.1 \%$ tropic amide, both eyes were examined with stereoscopic slit lamp biomicroscopy with a handheld lens 90D for signs of DR, indirect ophthalmoscopy and OCT images were obtained using (RS-3000 Advance; Nidek, Japan). Age, sex, duration of diabetes (in years), and mean $\mathrm{HbA} 1 \mathrm{c}$ were obtained from the patients' charts.

\section{OCT imaging and layer segmentation:}

Both eyes of every subject were imaged with NIDEK Optical Coherence Tomography (RS-3000 Advance; Nidek, Japan) with the image filing software NAVIS-EX, RS-3000 Advance OCT. The Patients were asked to fixate on an internal fixation target during the scanning process and SD-OCT images were obtained. This instrument has a light source of $880 \mathrm{~nm}$ wavelength. Using The MACULA RADIAL protocol evaluates $6 \times 6 \mathrm{~mm}$ area centered on the fovea as possible. The patient's fundus is scanned along equally spaced radial lines that intersect at the center of the macula to obtain OCT images. 12 scan lines with each spaced $15^{\circ}$ apart from each other. The Macula radial scan pattern evaluates a $6 \times 6-\mathrm{mm}$ area centered on the fovea with B-scan lines, each consisting of 1,024 A scans per line. Retinal thickness was automatically calculated in the ETDRS (early treatment diabetic retinopathy study) areas (consisting of 2 concentric rings inner and outer rings of 3 and $6 \mathrm{~mm}$ diameter, respectively). The inner and the outer rings are divided into four quadrants (nasal, superior, temporal and inferior quadrant).

The mean thickness of targeted retinal layers in each of the ETDRS subfields were recorded. Retinal fiber layer (NFL) and ganglion cell layer (GCC) complex was calculated automatically in the Macula Radial protocol from the inner border of NFL to the outer border of GCL.

If any instrument error in the automatic segmentation of retinal layers was documented by the second examiner, the manual correction was done with proper repositioning of layers into proper place using high magnification images, in order to redefine the retinal profile.

\section{Statistical analysis:}

Both eyes of each subject were included for the statistical analysis. All data were collected, tabulated and statistically analyzed using SPSS 
20.0 for windows (SPSS Inc., Chicago, IL, USA) and MedCalc 13 for windows (MedCalc Software bvba, Ostend, Belgium). Quantitative data were expressed as the mean \pm SD and (95\% confidence interval of mean) and qualitative data were expressed as absolute frequencies (number) and relative frequencies (percentage). Continuous data were checked for normality by using Shapiro Walk test. Mann Whitney U-test was used to compare between two groups of non-normally. Percent of categorical variables were compared using Chisquare test or Fisher's exact test when appropriate. We considered all zones as repeated measures of the same subject with split this into two groups (cases and control) so analysis was done by Splitplot (mixed design) ANOVA. All tests were two sided. $p$-value $<0.05$ was considered statistically significant (S), $p$-value $<0.001$ was considered highly statistically significant (HS), and $p$-value $\geq 0.05$ was considered statistically Non-Significant (NS).

In current study, we measured for every subject 8 measurements of retinal thickness in each eye, corresponding to a certain zone of retina in each eye so we have overall 16 measurements for every subject, we can consider them as a repeated measurements as these measurement is done for a single variable but in different zones. In other hand our study aim to get difference between control and diabetic as regard retinal thickness. We postulate null hypothesis that there is no difference between control and diabetic as regard mean of retinal thickness in different zones according to this hypothesis we will use split plot ANOVA (SPANOVA) that have been split dependent variable (retinal thickness) on two "factors" (independent variables), where one factor is "within-subjects" factor (control versus diabetic) and the other factor is a "betweensubjects" factor (zones). By SPANOVA, we get a linear regression model provide a proof that retinal thickness is dependable on zone of measurement while not depend on group that subject is belong however the model has drawbacks, first one; large mean square of error of zones, this mean that variability in retinal thickness in different zones is unexplained random error, the second drawback; the model cannot test difference between retinal thickness of control and retinal thickness of diabetic in each zones independent from other zones so to aid in solving these issues, we compare retinal thickness in each zone of control with retinal thickness in corresponding zone of case using independent samples Student's $t$-test. The significance level of 0.05 for multiple comparisons with Bonferroni correction $(0.05 / 16=.003)$.

\section{Results}

\section{Demographics:}

In total, 36 consecutive patients with DM type 1 were included in the study all of them had no DR and 36 healthy controls matched for age and sex. There was insignificant difference in age $(p=0.820,95 \%$ CI 19.87 to 21.39$)$ and $\operatorname{sex}(p=$ 0.527). Most patients were in reasonable glycaemic control (mean $\mathrm{HbA} 1 \mathrm{c}=7.38 \%$; $\mathrm{SD}=0.24 \%$ ) and mean duration of $\mathrm{DM}$ (6.94 years; $\mathrm{SD}=1.32$ years).

Table (1): Comparison between studied groups as regard demographic data.

\begin{tabular}{|c|c|c|c|c|c|c|}
\hline $\begin{array}{l}\text { Demographic } \\
\text { data }\end{array}$ & \multicolumn{2}{|c|}{$\begin{array}{c}\text { Cases } \\
(\mathrm{N}=36)\end{array}$} & \multicolumn{2}{|c|}{$\begin{array}{l}\text { Control } \\
(\mathrm{N}=36)\end{array}$} & Test & $\begin{array}{c}p- \\
\text { value }\end{array}$ \\
\hline \multirow[t]{2}{*}{$\begin{array}{l}\text { Age (years): } \\
\quad \text { Median (IQR) } \\
\quad(95 \% \mathrm{CI})\end{array}$} & \multicolumn{2}{|c|}{$\begin{array}{l}21.00(19-23) \\
(19.87-21.39)\end{array}$} & \multicolumn{2}{|c|}{$\begin{array}{l}20.00(19-22) \\
(19.76-22.29)\end{array}$} & \multirow[t]{2}{*}{$-0.227 \bullet$} & \multirow[t]{2}{*}{0.820} \\
\hline & No. & $\%$ & No. & $\%$ & & \\
\hline $\begin{array}{l}\text { Sex: } \\
\quad \text { Female } \\
\text { Male }\end{array}$ & $\begin{array}{l}29 \\
7\end{array}$ & $\begin{array}{l}80.6 \\
19.4\end{array}$ & $\begin{array}{l}31 \\
5\end{array}$ & $\begin{array}{l}86.1 \\
13.9\end{array}$ & $0.400 t$ & 0.527 \\
\hline $\begin{array}{ll}\cdot & : \text { Mann W } \\
\ddagger & : \text { Chi-squa } \\
p \text {-value }<0.05 \text { is } \\
\mathrm{N} \quad: \text { Total nur } \\
95 \% \mathrm{CI}: 95 \% \text { Con }\end{array}$ & $\begin{array}{l}\text { iitney L } \\
\text { e test. } \\
\text { gnifica1 } \\
\text { aber of } \\
\text { inee }\end{array}$ & best. & & $\begin{array}{l}\text { No. : I } \\
\% \text { : I } \\
\text { SD : S } \\
\text { Sig. : } \\
\text { IQR : I }\end{array}$ & $\begin{array}{l}\text { Number. } \\
\text { Percent. } \\
\text { Standard De } \\
\text { Significanc } \\
\text { Interquartile }\end{array}$ & iation. \\
\hline
\end{tabular}

Table (2): Comparison between studied groups as regard clinical data and laboratory findings.

\begin{tabular}{|c|c|c|c|c|c|}
\hline \multirow{2}{*}{$\begin{array}{l}\text { Clinical data and } \\
\text { laboratory findings }\end{array}$} & \multicolumn{2}{|c|}{$\begin{array}{c}\text { Cases } \\
(\mathrm{N}=36)\end{array}$} & $\begin{array}{l}\text { Control } \\
(\mathrm{N}=36)\end{array}$ & \multirow[t]{2}{*}{ Test } & \multirow{2}{*}{$\begin{array}{c}p- \\
\text { value }\end{array}$} \\
\hline & \multicolumn{2}{|c|}{ Mean \pm SD } & Mean \pm SD & & \\
\hline Pulse & \multicolumn{2}{|c|}{$69.91 \pm 6.38$} & 72.8 & -1. & 0.154 \\
\hline $\mathrm{SBP}(\mathrm{mm}$ & \multicolumn{2}{|c|}{$119.30 \pm 5.62$} & 118. & -0 & 0.356 \\
\hline $\mathrm{DBP}(\mathrm{mmHg})$ & \multicolumn{2}{|c|}{$77.91 \pm 3.45$} & 77.36 & -0.4 & 0.626 \\
\hline IOP of right eye $(\mathrm{mmHg})$ & \multicolumn{2}{|c|}{$15.19 \pm 1.72$} & 15.5 & $-0.794 \bullet$ & 0.427 \\
\hline (mmHg) & \multicolumn{2}{|c|}{$14.72 \pm 1.66$} & $15.52 \pm 1.42$ & $-2.221 \bullet$ & 0.260 \\
\hline Duration of DM (years) & \multicolumn{2}{|c|}{$6.94 \pm 1.32$} & & & \\
\hline HBA1c $(\%)$ & \multicolumn{2}{|c|}{$7.38 \pm 0.24$} & & & \\
\hline \multirow{2}{*}{\multicolumn{2}{|c|}{$\begin{array}{l}\text { - : Mann Whitney U-test. } \\
p \text {-value }<0.05 \text { is significant. }\end{array}$}} & $\mathrm{DM}$ & \multicolumn{2}{|c|}{ : Diabetes Mellitus. } & \\
\hline & & SBP & Systolic & (n) & \\
\hline \multicolumn{2}{|c|}{$\mathrm{N}$ : Total number of subject. } & DBP & : Diastoli & oo & ure \\
\hline \multicolumn{2}{|c|}{$\begin{array}{l}\text { No. : Number. } \\
\% \text { : Percent }\end{array}$} & IOP & : Intraocu & Pressu & \\
\hline \multicolumn{2}{|l|}{$\% \quad$ : Percent. } & & Mi11: & & \\
\hline \multicolumn{2}{|l|}{ SD : Standard Deviation. } & Wh & . Uilye & & \\
\hline
\end{tabular}

\section{Retinal measurement analysis:}

A slip-plot (mixed design) ANOVA was conducted to investigate the impact of diabetes and zones of ETDRS map on macular nerve fiber layer and ganglion cell layer thickness. There was insignificant main effect of group, $\mathrm{F}=2.952, p=.090$. Additionally, there was insignificant interaction between group and zones of ETDRS, $\mathrm{F}=.821$, $p=.548$ as shown in (Table 3 ).

By SPANOVA, we get a linear regression model provide a proof that retinal thickness is dependable 
on zone of measurement while not depend on group that subject is belong however the model has drawbacks, first one; large mean square of error of zones, this mean that variability in retinal thickness in different zones is unexplained random error, the second drawback; the model cannot test difference between retinal thickness of control and retinal thickness of diabetic in each zones independent from other zones so to aid in solving these issues, we compare retinal thickness in each zone of control with retinal thickness in corresponding zone of case using independent samples Student's $t$-test. The significance level of 0.05 for multiple comparisons with Bonferroni correction $(0.05 / 16=.003)$.

Table (3): Tests of effects (Within-Subjects and betweensubjects) on retinal thickness ( $\mathrm{m}$ ) by using Splitplot (mixed design) ANOVA.

\begin{tabular}{llllll}
\hline Source & d.f. & \multicolumn{1}{c}{ SS } & \multicolumn{1}{c}{ MS } & \multicolumn{1}{c}{ F } & $p$-value \\
\hline Intercept & 1 & 975862.709 & 975862.709 & 20231.301 & $<0.001$ \\
Zones & 5.691 & 88134.138 & 15486.716 & 639.834 & $<0.001$ \\
Error (zones) & 398.367 & 9642.168 & 24.204 & & \\
Group & 1 & 142.383 & 142.383 & 2.952 & 0.090 \\
Zones x group & 5.691 & 113.131 & 19.879 & 0.821 & 0.548 \\
Error & 70 & 3376.470 & 48.235 & & \\
Total & 480.749 & 101408.29 & & & \\
\hline d.f. : Degree of Freedom. & \multicolumn{2}{c}{ SS : Type III sum of squares. } \\
$p$-value <0.05 is significant. & MS : Mean Square. & \\
$p$-value <0.001 is highly significant. & F : Fisher's Ratio. &
\end{tabular}

Mean $( \pm S D)$ and mean difference of retinal nerve fiber layer and ganglion cell layer thickness in all patients with diabetes compared to healthy controls is shown in (Table 4). By independent samples Student's $t$-test there were no significant difference between diabetic patients and healthy controls except in temporal zone of inner circle in the left eye was statistically significant thinning in diabetic patient by only $2.02 \mathrm{~m}$ hich is clinically insignificant.

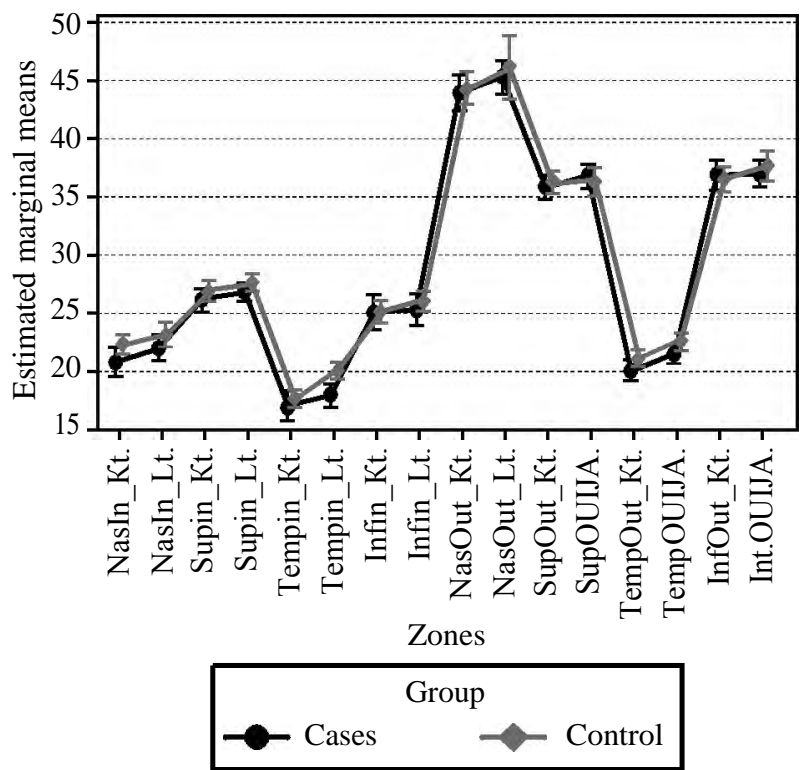

Fig. (1): Profile plots shows comparison between studied groups as regard estimated marginal means of retinal thickness in different zones; marker represent estimated marginal mean, Y-error bar represent 95\% confidence interval of estimated marginal mean.

Table (4): Comparison between studied groups as regard retinal thickness (

\begin{tabular}{|c|c|c|c|c|c|c|c|c|}
\hline \multirow{2}{*}{ Zone } & \multicolumn{2}{|c|}{$\begin{array}{l}\text { Retinal thickness (m) } \\
\text { of cases }(\mathrm{N}=36)\end{array}$} & \multicolumn{2}{|c|}{$\begin{array}{l}\text { Retinal thickness ( } \\
\text { of control }(\mathrm{N}=36)\end{array}$} & \multicolumn{2}{|c|}{$\begin{array}{l}\text { Retinal thickness } \\
\text { difference ( }\end{array}$} & \multirow{2}{*}{ Test* } & \multirow{2}{*}{$p$-value } \\
\hline & Mean \pm SD & $(95 \% \mathrm{CI})$ & Mean \pm SD & $(95 \% \mathrm{CI})$ & Mean \pm SD & $(95 \% \mathrm{CI})$ & & \\
\hline 1 & $20.91 \pm 3.68$ & $(19.67-22.16)$ & $22.50 \pm 2.32$ & $(21.71-23.28)$ & $-1.58 \pm 0.72$ & $(-3.03--0.13)$ & -2.182 & 0.033 \\
\hline 2 & $22.13 \pm 3.07$ & $(21.09-23.17)$ & $23.27 \pm 2.88$ & $(22.30-24.25)$ & $-1.33 \pm 0.70$ & $(-2.74-0.07)$ & -1.887 & 0.063 \\
\hline 3 & $26.25 \pm 3.01$ & $(25.22-27.27)$ & $27.02 \pm 2.78$ & $(26.08-27.96)$ & $-0.77 \pm 0.68$ & $(-2.14-0.58)$ & -1.137 & 0.259 \\
\hline 4 & $26.88 \pm 2.39$ & $(26.07-27.70)$ & $27.66 \pm 2.07$ & $(26.96-28.36)$ & $-0.94 \pm 0.53$ & $(-2.01-0.12)$ & -1.764 & 0.082 \\
\hline 5 & $17.13 \pm 3.81$ & $(15.84-18.43)$ & $17.77 \pm 2.35$ & $(16.98-18.57)$ & $-0.63 \pm 0.74$ & $(-2.13-0.85)$ & -0.854 & 0.396 \\
\hline 6 & $18.08 \pm 2.87$ & $(17.11-19.05)$ & $20.11 \pm 2.12$ & $(19.39-20.82)$ & $-2.02 \pm 0.59$ & $(-3.21--0.84)$ & -3.407 & 0.001 \\
\hline 7 & $25.19 \pm 4.34$ & $(23.72-26.66)$ & $25.25 \pm 2.70$ & $(24.33-26.16)$ & $-0.55 \pm 0.85$ & $(-1.76-1.65)$ & -0.065 & 0.984 \\
\hline 8 & $25.41 \pm 3.74$ & $(24.14-26.68)$ & $26.13 \pm 2.67$ & $(25.23-27.04)$ & $-0.80 \pm 0.78$ & $(-2.37-0.75)$ & -1.026 & 0.309 \\
\hline 9 & $44.02 \pm 4.65$ & $(42.45-45.60)$ & $44.38 \pm 4.13$ & $(42.98-45.78)$ & $-0.36 \pm 1.03$ & $(-2.42-1.70)$ & -0.348 & 0.729 \\
\hline 10 & $45.36 \pm 4.16$ & $(43.95-46.77)$ & $44.16 \pm 8.00$ & $(43.45-48.87)$ & $-0.91 \pm 1.49$ & $(-3.90-2.07)$ & -0.612 & 0.543 \\
\hline 11 & $35.88 \pm 2.99$ & $(34.87-36.90)$ & $36.36 \pm 2.91$ & $(35.37-37.34)$ & $-0.47 \pm 0.69$ & $(-1.86-0.91)$ & -0.678 & 0.500 \\
\hline 12 & $36.91 \pm 3.07$ & $(35.87-37.95)$ & $36.36 \pm 3.68$ & $(35.11-37.60)$ & $0.47 \pm 0.80$ & $(-1.12-2.07)$ & 0.589 & 0.558 \\
\hline 13 & $20.25 \pm 2.57$ & $(19.37-21.12)$ & $21.25 \pm 2.00$ & $(20.57-21.92)$ & $-1.00 \pm 0.54$ & $(-2.08-0.08)$ & -1.837 & 0.070 \\
\hline 14 & $21.61 \pm 2.30$ & $(20.83-22.93)$ & $22.69 \pm 2.24$ & $(21.93-23.45)$ & $-1.05 \pm 0.53$ & $(-2.11-0.004)$ & -1.986 & 0.051 \\
\hline 15 & $36.91 \pm 3.73$ & $(35.68-38.20)$ & $36.58 \pm 2.88$ & $(35.60-37.55)$ & $0.36 \pm 0.78$ & $(-1.20-1.92)$ & 0.459 & 0.647 \\
\hline 16 & $37.02 \pm 3.32$ & $(35.90-38.15)$ & $37.75 \pm 3.60$ & $(36.53-38.96)$ & $-0.86 \pm 0.82$ & $(-2.51-0.79)$ & -1.039 & 0.303 \\
\hline
\end{tabular}

\begin{tabular}{ll}
\hline 1: Rt. Nasal Inner. & $9:$ Rt. Nasal Outer. \\
2: Lt. Nasal Inner. & $10:$ Lt. Nasal Outer. \\
3: Rt. Superior Inner. & $11:$ Rt. Superior Outer. \\
4: Lt. Superior Inner. & $12:$ Lt. Superior Outer. \\
5: Rt. Temporal Inner. & $13:$ Rt. Temporal Outer. \\
6: Lt. Temporal Inner. & $14:$ Lt. Temporal Outer. \\
7: Rt. Inferior Inner. & $15:$ Rt. Inferior Outer. \\
8: Lt. Inferior Inner. & $16:$ Lt. Inferior Outer.
\end{tabular}

$\begin{array}{ll}\mathrm{N} & : \text { Total number of subject. } \\ \mathrm{SD} & : \text { Standard Deviation. } \\ \mathrm{SE} & : \text { Standard Error. } \\ 95 \% \mathrm{CI}: & \text { 95\% Confidence Interval of mean. } \\ * & : \text { Independent samples Student's } t \text {-test } \\ p \text {-value } & <0.003 \text { is significant. }\end{array}$

$p$-value $<0.003$ is significant. 


\section{Discussion}

The results presented in this cross-sectional study demonstrate that the macular Nerve Fiber Layer (NFL) and Ganglion Cell Layer (GCL) thickness are not statistically different in diabetic patients compared with that of healthy controls.

Pekel et al., [7] in reported that patients with type 1 diabetes and healthy controls had similar RNFL thickness and GCL + IPL thickness in all quadrants. On the other hand, diabetic eyes had higher percentage of binocular RNFL asymmetry. Vujosevic et al., [8] reported that there was a different thickness profile in GCL complex and NFL among 3 examined groups (control, patients with DM Type 1, and DM Type 2), such a model estimated that GCL complex and NFL was thinner in patients with DM Type 1 versus controls, although not reaching statistical significance and significant in patients with DM Type 2. Elhabashy et al., [9] reported that no statistically significant differences were found between patients with and without microvascular complications compared with controls regarding nerve fiber layer volume and ganglion cell layer area in both eyes and suggested that there is no advantage of performing OCT routinely in patients with type $1 \mathrm{DM}$ without retinopathy in order to detect preclinical retinal changes. This study was done on a smaller sample size: 30 patients and 20 participants in the control group. And with only measurement of 2 outcomes temporal and nasal Nerve Fiber Layer (NFL) and Ganglion Cell Layer (GCL) in comparison with the 8 ETDRS outcomes in the present study. Ciresi et al., [10] demonstrated that retinal thickness in patients with type 1 diabetes with minimal or no retinopathy is not significantly different from that of the control group. No difference was found between patients with or without minimal DR and the control group for all OCT parameters investigated. This study suggests that there is no advantage in performing OCT routinely in patients with type 1 diabetes without or with minimal DR in the absence of macular edema. Scarinci et al., [11] reported that the peripapillary retinal nerve fiber layer NFL was slightly thinner in all explored quadrants, even if the reduction was not significant in type 1 diabetes eyes versus control eyes. In the macular area, NFL thickness was slightly thinner in all explored sectors, especially in the nasal and inferior quadrant in all type 1 diabetes eyes versus control eyes. However, this difference did not reach statistical significance. No significant differences in RNFL thickness were found between no DR and NPDR eyes. The thickness values of each different layer in all quadrants of GCL, IPL, OPL, ONL,
RPE, INL, and PR showed no statistically significant differences between diabetics and controls. Current study supports these finding.

In contrast to this study Biallosterski et al., [12] demonstrated a significantly decreased pericentral retinal thickness in patients with DM type 1 with minimal DR compared to a healthy control group. In the other macular areas, no significant difference in retinal thickness measurements could be found. This is may due to longer duration of diabetes and higher levels of HbA1c. Van Dijk et al., [13] has demonstrated that the thinning of the inner retinal layers specifically NFL, GCL, and IPL in the macula of patients with type I diabetes with no or minimal diabetic retinopathy is progressive over time and is related to disease duration but occurs independently of retinal vasculopathy. But this study was done on a different age range from 20 to 41 years and longer duration of insulin treatment from 10 to 24 years which were different from those of the present study.

The strength of our study compared to other studies is the strict inclusion of patients with type 1 diabetes only. We feel that this group of patients, with a well known duration of their disease, is a more homogeneous group of patients compared to a mix of type 1 and type 2 patients as used in other studies and in careful exclusion of patients with macular edema, mild DR or Non Proliferative DR (NPDR). The majority of clinical studies have been performed on heterogeneous groups of patients, with macular edema and/or including patients with type 2 diabetes. We measured the nerve fiber layer and the ganglion cell layer, which are the layers with the most neural cells. These cells are most vulnerable to diabetes-related degeneration. We used the ETDRS map with 8 measurements to detect tiny changes. We included both eyes measurement of every participant to increase the power in our study with proper statistical analysis.

This study has several limitations; firstly we have not performed Fundus Fluorescein Angiography (FFA), which might show the earliest retinopathy findings that could not be noticed by routine retinal examination. But there were no clear clinical indications for FFA in our cases. Another limitation is the relatively small sample size. The OCT imaging was done by single examiner. And grading of the severity and progression of DR was done by two examiners through ophthalmologic examination including indirect fundoscopy, slit-lamp stereo biomicroscopy and one examiner has assessed OCT images of retinopathy changes. 
In addition, the presence of undiagnosed diabetics most likely has led to underestimation, not overestimation, of the difference in inner retinal thickness between patients and controls.

Furthermore, larger and longitudinal cohort studies are needed to better evaluate and correlate microvascular and neural changes in the retina in DM type 1.

\section{Conclusion:}

Nerve Fiber Layer (NFL) and Ganglion Cell Layer (GCL) were not affected in early type 1 diabetic patient without minimal DR in the absence of macular edema. The theory of early neurodegenerative changes preceding the microvasculopathy in DM type 1 patient is not supported.

Therefore, there is no advantage in performing OCT routinely in patients with type 1 diabetes without minimal DR.

\section{Acknowledgment:}

We wish to express our sincere appreciation to Dr. Hesham Mohamed Gharieb, Department of Ophthalmology, Faculty of Medicine, Ain-Shams University, for his great effort in performing OCT.

We would like to thank all the patients for their cooperation during the study period.

\section{References}

1- ROMERO-AROCA P., BAGET-BERNALDIZ M., PAREJA-RIOS A., et al.: Diabetic Macular Edema Pathophysiology: Vasogenic versus Inflammatory. J. Diabetes Res. 2016: 2156273, 2016.

2- KÖNIGSREUTHER K.A. and JONAS J.B.: Optic disc morphology in diabetes mellitus. Graefes. Arch. Clin. Exp. Ophthalmol., 233 (4): 200-4, 1995.

3- BARBER A., LIETH E., KHIN S., et al.: Neural apoptosis in the retina during experimental and human diabetes.
Early onset and effect of insulin. J. Clin. Invest., 102: 783-91, 1998

4- RUNGGER-BRÄNDLE E., DOSSO A. and LEUENBERGER P.: Glial reactivity, an early feature of diabetic retinopathy. Invest. Ophthalmol. Vis. Sci., 41: 1971-80, 2000.

5- VAN DIJK H.W., VERBRAAK F.D., KOK P.H., et al.: Decreased retinal ganglion cell layer thickness in patients with type 1 diabetes. Invest. Ophthalmol. Vis. Sci., 51: 3660-5, 2010

6- JAFFE G.J. and CAPRIOLI J.: Optical coherence tomography to detect and manage retinal disease and glaucoma. Am. J. Ophthalmol., 137 (1): 156-69, 2004.

7- PEKEL E., ALT1NC1K S.A. and PEKEL G.: Evaluation of optic disc, retinal nerve fiber and macular ganglion cell layers in pediatric diabetes. Int. Ophthalmol., 2017: $1-7,2017$.

8- VUJOSEVIC S., MURACA A., ALKABES M., et al.: Early microvascular and neural changes in patients with type 1 and type 2 diabetes mellitus without clinical signs of diabetic retinopathy. Retina, 0: 1-11, 2017.

9- ELHABASHY S.A., ELBARBARY N.S., NAGEB K.M., et al.: Can optical coherence tomography predict early retinal microvascular pathology in type 1 diabetic adolescents without minimal diabetic retinopathy? A singlecentre study. J. Pediatr. Endocrinol. Metab., 28 (1-2): 139-46, 2015

10- CIRESI A., AMATO M.C., MORREALE D., et al.: OCT is not useful for detection of minimal diabetic retinopathy in type 1 diabetes. Acta. Diabetol., 47 (3): 259-63, 2010.

11- SCARINCI F., PICCONI F., VIRGILI G., et al.: Single Retinal Layer Evaluation in Patients with Type 1 Diabetes with No or Early Signs of Diabetic Retinopathy: The First Hint of Neurovascular Crosstalk Damage between Neurons and Capillaries? Ophthalmologica, 237 (4): 223-31, 2017.

12- BIALLOSTERSKI C., VAN VELTHOVEN M.E. MICHELS R.P., et al.: Decreased optical coherence tomography measured pericentral retinal thickness in patients with diabetes mellitus type 1 with minimal diabetic retinopathy. Br. J. Ophthalmol., 91 (9): 1135-8, 2007.

13-VAN DIJK H.W., KOK P.H., GARVIN M., et al.: Selective loss of inner retinal layer thickness in type 1 diabetic patients with minimal diabetic retinopathy. Invest. Ophthalmol. Vis. Sci., 50 (7): 3404-9, 2009. 


\section{تقييم توموجرافى لبعض الطبقات العصبية للشبكية الإنية

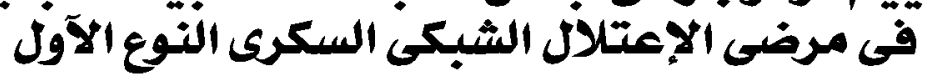

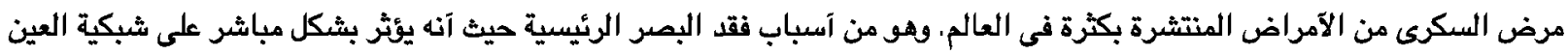

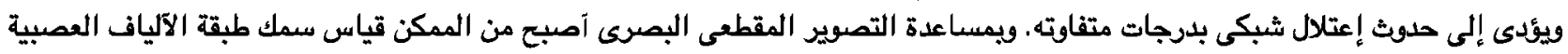

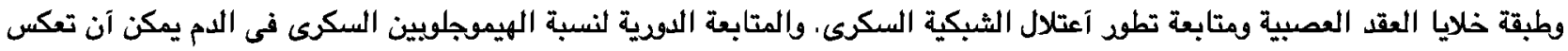

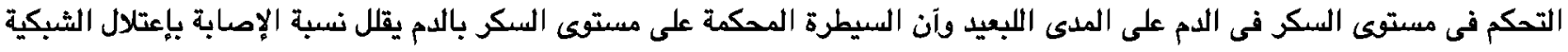
السكرى فى مرضى السكرى بنوعية الآولل والثانى.

وتهدف دراستنا إلى تقييم سمك طبقة الآلياف العصبية وطبقة خلايا العقد العصبية بالتصوير المقطعى البصرى ومقارنته بين مرضى السكر من النوع الآول بدون وجود إعتلال سكرى فى الشبكية ويين مشاركين طبيهين وخالين من الآمراض.

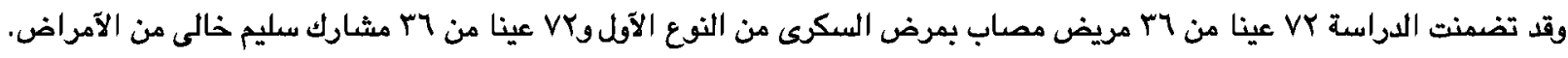

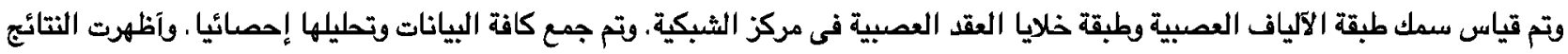

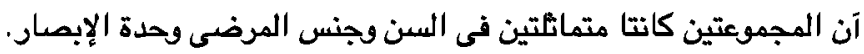

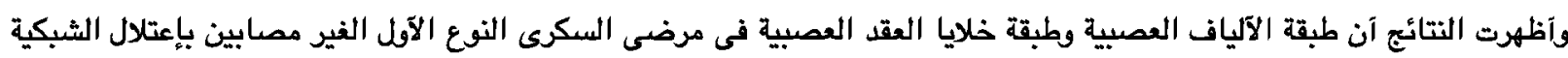
إكينيكيا آقل سمكا فى بعض الآجزاء وآكثر سمكا فى البعض الآخر ولكن الفارق بسيط وغير معبر إحصائيا وليس ذو قيمة إلكينيكيا.

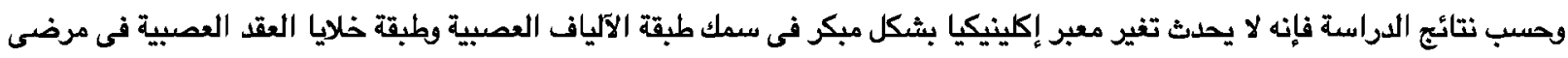

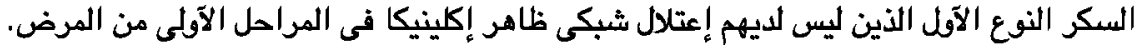

